\title{
Photography and the Discovery of the Double Helix Structure of DNA
}

\section{Author Information}

\section{First author:}

Jose Cuevas, Ph. D.

San Bernardo 89, 5 Izq., 28015 Madrid. Spain

Visiting Professor of Film and Media Studies

Complutense University of Madrid and Carlos III University of Madrid

E-mail: joscueva@pdi.ucm.es

Jose Cuevas is a photographer and documentary filmmaker, author of numerous documentaries and photographic exhibitions. He has published articles and books related to his main subject of investigation: the role played by photography in the acquisition of scientific knowledge. Personal and academic interests are focused on the study of the relationship between art and science through the theory and practice of photography. His most recent book is Photography and Knowledge: Photography in the Age of Electronics: From its Origins to 1975 published by Complutense University of Madrid, Spain in 2009.

\section{Second author:}

Laurence E. Heglar, Ph.D.

Juan de Urbieta 12, 3 B

28007 Madrid, Spain

E-mail: 1heglar@syr.edu

Laurence Heglar is Adjunct Professor of Psychology at Syracuse University, Madrid Spain Campus. His research interests include language development, methodological issues in the social sciences and the philosophy of science. He is presently working on a study of the American philosopher John Dewey. His most recent publication is 'Cognition and the Argument from Design', American Psychologist, 51(1), 1996, 57-58. 


\section{Photography and the Discovery of the Double Helix Structure of DNA}

The development of X-ray diffraction photography was central to the discovery of the helical structure of DNA in 1953. Unfortunately the story of how this technique was developed receded into the background as subsequent attention focused on the moment of discovery by Watson and Crick. As a result the importance of photography as 'data' and the role it plays in scientific discovery is underplayed. We seek to rectify this situation by presenting this story and by drawing conclusions about the importance of this form of photography in scientific investigation as well as for the insights it gives us regarding the process of discovery.

Keywords: X-ray diffraction photography, Rosalind Franklin, James Watson, Francis Crick, helical structure of DNA, scientific discovery.

If physics was the big star of modern science in the first half of the XX century due mainly to the success of relativity, quantum mechanics and advances in nuclear physics, molecular biology was the great protagonist in the second half of the century not only in science but in society as a whole. The final step of this process is well known by modern societies: the current knowledge and practices in cellular reproduction, the genomic classification of hundreds of species, or cellular cloning, are subjects which transcend the scope of 'pure' science. This shift was carried out progressively in conjunction with the application of instruments and equipment developed for the physical sciences to the study of living organisms. One of the goals of the present article is to describe the process by which technical image, more precisely photography, has had in this area of discovery. Specifically, we will focus on X-ray diffraction spectrography as developed since the beginning of the last century with silver halide 
photographic plates as the medium for visualizing diffraction patterns. Within the history of this technology a particular event stands out - the use of x-ray diffraction and complementary tools for the drafting of a double-helical model as the significant structure of DNA.

There have been numerous studies of the facts involved in the discovery of the DNA double helix structure in the recent history of science, but rarely have we found a specific interest in the process of creating an adequate photographic record which made this discovery possible. In the world of modern science, a premium is placed on those moments when the big discovery is made, when the years of technical work reach a point such that it is possible to achieve a major new insight into some phenomena. The technical work is generally hidden from view because the public, and often the scientists themselves, consider this aspect as subsidiary to the moment when it all comes together. Our goal is to draw attention to this work in photography. Our findings surely dismantle this prejudice or forgetfulness of a technique which played such an essential part of this scientific advance.

This story will also permit us to reflect on the use of the photograph and associated techniques in the process of discovery. Describing this process will allow us to bring into consideration important relationships between the investigator, the photographed 'object', and the technical means for displaying and working on the object.

In scientific activity the purported goal of photographic imaging is to attempt to mimetically capture things as they occur in the world (Galison 1997). This goal fits in well with our everyday notion of empiricism, but it is overly simplified in that it hides from view the investigator's role in actively manipulating both instruments and materials in order to achieve desired results. The investigator is more than a spectator of physical processes and structure, the investigator must interact with the materials such that relevant qualities or characteristics of the 
material can emerge. The desired result is the achievement of a physical record or data that will lend itself to inference and which can then be used for further investigative activities. In this way scientific imaging differs from artistic photography in which composition and the techniques used in creating the image have the desired end of producing and terminating with aesthetic enjoyment.

We shall also see in this example that the modern production of an image, used for purposes of investigation, is the result of a collaborative effort among investigators, raising questions about our continued insistence on attributing discovery to individuals. A historical analysis of the conditions which gave rise to the discovery of the helical structure of the DNA molecule demonstrates that the process of discovery cannot be reduced to an instance of 'insight' or an explanation by some other psychological mechanism. Attention must be given to the conditions under which such insight was made possible. In our example case some interesting issues about the authorship of this discovery have been raised.

\section{Methodology}

The reconstruction of the most relevant facts of this history and the study of their precedents and consequences has been carried out by means of bibliographical research in specialized magazines and books, as well as interviews carried out with specialists from CSIC. ${ }^{1}$ In our bibliographical study we have reviewed Nature, number by number, between the years of 1913 to 1974, in addition to other selected journals and books. Our attention, although centered on photography, has not omitted other types of 'technological imaging' and representational formats such as those produced by analog electronic devices, models, or stereochemistry. Within the scope of photography our main attention has been given to silver halide photography, especially as a part of X-ray diffraction spectrography, but also to the important role it plays in 
other types of spectrographies, photomicrography, electron diffraction technique and electron microscopy.

\section{An Historical Overview - Quantum Physics in Biology}

The history of modern molecular biology and genetics has its origin in the works of Gregor Mendel. In 1866 this scientist announced the laws of heredity without any knowledge of genes, mutations or chromosomes by only taking into account the hybridization of peas. The method used by Mendel was simple observation of the physical features of pea seeds, their fruits and their most outstanding characteristics, and from there establishing numerical predictions. The term 'element' in his work, today known as a gene, named every single observable characteristic of the peas such as the color, texture or size. His theories went unattended during decades until several authors, Hugo De Vries among them, vindicated their relevance.

Observation in this case made it possible to depart from a hypothetical entity towards a new reality and its constituent parts, in the future called a 'gene'. Following this direction and with the help of microscopes of higher resolution and the use UV radiation scientists were able to identify cells and their parts - the nucleus, the cytoplasm and in the interior of the latter the chromosomes, proteins and nucleic acids. At the beginning proteins attracted the most attention of scientists, but progressively their interest moved towards nucleic acids and especially to DNA, first detected somewhat imprecisely in 1871 by F. Miescher (Olby 1974a).

At the beginning of the XX century physics and biology started to strengthen their relationship. The same pioneer in molecular biology Hugo de Vries discovered in 1902 (the year Max Planck formulated his quantum theory) the role played by cell mutations and again the explanation was given in terms of discrete quantities, in this case applied to the descendant line of a species. It is not a coincidence that his theory was denominated the quantum theory of 
biology by Erwin Schrödinger, one of the most representative scientists of this new trend in physics (Schrödinger 1967).

In the meantime, observation instruments underwent significant evolution with the arrival of X-rays. The discovery of the dispersion effect of this type of rays in a zinc blende crystal in 1912 by Laue and Knipping (Tutton 1913) was the origin of X-ray diffraction spectrography. Once the rays scattered by the crystals were registered on photographic plates, scientists such as William L. Bragg initiated the process of deciphering the patterns formed in the emulsions. At the beginning of the second decade of this century new X-ray tubes made possible the crystallographic study of biologic substances in the form of powder or fiber, motivating the construction of cylindrical cameras and X-ray goniometers in order to produce rotation and oscillation pictures (Olby, 1974b). Bragg himself was very aware of the advances made a decade later by W. Astbury and J. D. Bernal who applied this technique to the study of molecular structures of different organic materials such as hair, feathers, bones, silk or cotton; or to aminoacids, vitamins, proteins and viruses, respectively (Bragg 1933).

Astbury's work in the textile industry helped him establish a helical model for the structure of queratine, a constituent fiber of wool. The photographic patterns did not have as high a contrast as those originated by crystals, but it was sufficient for the author to establish the presence of a double helix structure which he named 'alpha' and 'beta'. Although the discovery was a milestone in the study of biological molecules, the blurry images of the photographs were probably the reason why his model for the alpha-queratine was not entirely consistent with the atomic structure of the molecule. In fact it was M. L. Huggins, a scientist from Eastman Kodak Ltd. at Rochester N.Y. who pointed out the inconsistency after his work with the structure of gelatin, a decisive component of photographic film (Olby 1974b: 11). 
In 1936 important scientific encounters on molecular biology were held in Copenhagen. Most of the scientists came from areas of physics and their works were centered on the application of quantum chemistry to the study of genes and cell mutations with the help of X-ray diffraction. Among them, celebrated scientists such as Niels Bohr and Max Delbrück attended the meeting (Waddington 1969) That same year T. Caspersson was able to define chromosomes as a combination of proteins and deoxyribonucleic acid (DNA) (Darlington 1955). Two years later, in 1938, another meeting of geneticists and crystallographers was held near Copenhagen. One of the most celebrated contributions was given by C. D. Darlington who announced the detection of a series of bands attributable to the genes in the chromosome with the help of an optical microscope; and also the detection of a 'relational coiling' structure, a precursor of the DNA double helix which was confirmed years later by X-ray diffraction patterns (Waddington 1969). At the same time, new discoveries were made in this field such as the identification of the DNA macromolecule by R. Signer, T. Caspersson y E. Hammarsten, and the first x-ray diffraction photographs of hemoglobin crystals by M. Perutz, J. D. Bernal y I. Fankuchen (Bragg 1954). Using the first methods of isolating DNA fibers, Florence Bell took photographs of $2 \mathrm{~mm}$ wide slices that had been prepared with the Hammarsten technique. The results were outstanding, even though the A and B forms still appeared mixed up (Olby 1974b: 64). That same year of 1938, Astbury predicted that nucleic acid molecules might form 'the long scroll on which is written the pattern of life' (Olby 1974b: 68).

It is important to note at this point that the methodology for the study of molecular structures in these years depended upon multiple tools of observation and measurement, including the quantitative analysis of substances and the preparation of fibers and specimens by either optical or chemical means. In addition to X-ray diffraction other techniques are 
noteworthy, for example, ultraviolet and infrared microscopy, UV spectrography, birefringence studies, sedimentation techniques such as chromatography, electrophoresis and ultracentrifuge; electrolitic processes, staining techniques associated with UV photomicrography and Köhler illumination microscopy, calorimetrics and stretching processes, or the Feulgen Technique. Even more, the combination of UV microscopy along with the use of the camera lucida, a technique developed in the early XIX century, brought remarkable results with the first chromosomic lines and bands, drawn by T. S. Painter in 1933 (Olby 1974b: 103).

In the meantime across the Atlantic ocean, at the California Institute of Technology, T. H. Morgan who was very interested in the application of electron and X-ray diffraction to the study of molecules, started to recruit biologists and chemists with the intention of consolidating a highstandard scientific project. Among these scientists, Linus Pauling stood out for his work on the application of quantum mechanics principles to the study of molecules and chemical bonds. If physics was able to explain matter in terms of its atomic structure, molecular biology also wanted to attend to these tiny particles in order to explain the behavior of molecules, proteins and nucleic acids. Pauling's experimental and theoretical studies were to have significant repercussions in biochemistry and molecular biology during the coming decades, and especially for the work of Watson and Crick as they moved towards the discovery of the DNA double helix (Watson 1986) Years later Pauling, along with C. D. Coryell and A. E. Mirsky, was able to decipher the structure of hemoglobin and, by himself, formulate a theory of the structure and process of antibody formation (Pauling 1974).

First steps towards a big discovery

Prior to the outbreak of the Second World War the work being carried out by crystallographers J. D. Bernal and W. Astbury entered in a new phase of development as a result 
of the application of X-ray diffraction to complex molecules of organic elements. For a number of years Bernal as well as Joseph Needham, the biochemist and renown historian of science, had been insisting on the need to apply photographic crystallographic techniques to the study of fibers. In fact Bernal, in collaboration with D. Hodgkin, had been photographing protein crystals since 1934 and had drawn attention to the importance of their preparation, since more than 200 hours of exposure were needed. A few years later, working with I. Fankuchen, he began a detailed study of the VMT virus, using an X-ray monochromator tube designed by himself, with which he photographed fibers using exposures of more than 400 hours (Olby 1974b: 259). The worn-out and ramshackle laboratory of Bernal -in his own words - 'on the top floor of the DavyFaraday (Royal Institution), with an X-ray tube that worked about one day a fortnight between breakdowns, and vague prospects of getting three more and a few of my old cameras' (Olby 1974b: 273) surely played a decisive role in the careers of Crick, Franklin, Perutz and many others scientists who came to him for advice in this new field of science (Abir-Am 1997).

Astbury, for his part, started in 1938 along with F. O. Bell to take hundreds and hundreds of pictures of DNA fibers, arriving at the conclusion that the nucleotide chains formed a model or structure for the process of formation and reproduction. This was a key idea for the future development of molecular biology, especially regarding DNA (Astbury and Bell 1938). In fact, Astbury built a model of the acid structure with pieces of metal and rods which represented the position of bases, sugars and phosphates. The model very closely reproduced the positions of the bases and the distances between them that characterized the definitive model announced years later by J. Watson y F. H. C. Crick. It was assumed at the time that it was necessary to go beyond the data supplied by the photographic patterns and to build 3-D models which would permit one to see the structure of molecules in their integrity. In 1943, during the war, O. T. Avery 
announced that when DNA was transferred from one cell to another in the pneumococcus bacteria that it carried the genes of the host. This remarkable discovery confirmed his previous assumptions that this substance, and not the proteins as was commonly thought, was in charge of genetic transmission in heredity. The war was probably the reason why these revelatory ideas went unnoticed for more than a year and why scientists kept on thinking proteins were the substances responsible for heredity. In 1944, Avery in collaboration with C. M. MacLeod and M. McCarty published a detailed and clarifying report assuring definitely that deoxyribonucleic acid (DNA) was responsible for this task. These advances were given a strong theoretical push when Erwin Schrödinger gave a series of conferences in 1943 in Dublin, compiled later under the title What is Life? The Physical Aspect of the Living Cell. This was the first time that an outstanding figure representing wave mechanics had brought attention to the need for understanding biological processes under the perspective of this theory. The most acclaimed thesis in that book which attracted many physicists to biology was the understanding of organic molecules as 'aperiodic crystals' (Schrödinger 1967).

\section{Rosalind Franklin and Photograph $N^{\circ} 51$}

After the war, hundreds of crystallographers specializing in X-ray diffraction spectrography moved into the field of biology. Among them was Rosalind Franklin, one of the most debated scientific figures as a result of the doubt created around the authorship of the DNA double helix structure. Franklin dedicated many years of her career to analyzing, with the X-ray diffraction technique, the different types of carbon used for combustion and for gas masks employed by the soldiers during the recent war (Maddox 2003). In 1951 she joined the group of investigators at King's College of London where she was assigned to the study of organic 
molecules with the technique she knew profoundly - X-ray diffraction. This was her first experience in the field of biology.

At that time this type of technique for crystallographic analysis had a great reputation, being backed by very refined methods. Basically its operation required an X-ray tube, a highvoltage generator and a vacuum system with a receptacle for holding the specimen, sometimes located in the same camera. The reason for the latter is that X-rays get weaker when passing through air. Finally, a temperature control device for the receptacle is necessary in order to avoid extreme changes during the long exposures, which could be of minutes, days, or 'up to 200 hours or more for one photograph' (Olby 1974b: 254).

The work of deciphering of the internal structure of complex molecules as constituents of living beings cells was moving forward. In 1949 E. Chargaff, influenced by the work of Astbury and the theories of Schrödinger, called attention to the correspondence between the four bases which form DNA. Chromatographic technique, in which observable results are essential, was of great help in this fundamental step towards the determination of DNA structure, as Watson and Crick recognized years later (Olby 1974a). In 1951 Linus Pauling was able to reveal one of the structures of proteins - the alpha-helix - a discovery which he illustrated with a 3-D stereochemical model built out of wires and wooden balls. The next step in this direction was expected to be the determination of the structure of nucleic acids. Scientists on both sides of the Atlantic intensely photographed the crystalline fibers of these acids. At that time the methodology used to study proteins was determined by either of the two models represented by Bernal and Pauling. Bernal defended a direct means of observation based on the pictures produced by X-ray diffraction, while Pauling placed his confidence in quantum physicalchemical theory and tools. According to Pauling, the complexity of large molecules made it 
'unlikely that a complete structural determination of a protein will ever be made by X-ray methods alone' (Olby 1974b:269). As of matter of fact, in discovering the alpha-helix structure of proteins he had emphasized the study of stereochemical bonds more than fiber chains or diffraction patterns (Olby 1974b: 278). This attitude of Pauling towards X-ray diffraction, which he considered a tedious and boring technique (Olby 1974b: 273) and his excessive confidence in the predictive potential of the principles of quantum mechanics and on his resonance theory of chemical bonds over empirical data, are good reasons for us to think that while it was an orientation which helped him determine the alpha-helix structure of proteins, it was also the cause of his failure in defending a triple helix structure for the DNA (Chadarevian: 106 - 107). It should also be noted that the alpha-helix structure for proteins did not receive empirical verification until Perutz made X-ray diffraction photographs of its structure at the end of 1951, pictures captured with a cylindrical film designed for this purpose 'instead of the flat plates normally used' (Olby 1974b: 293 - 294). This inability to correctly interpret the crystallographic data is also found in Astbury's work. In 1951, Elwyn Beighton, a close collaborator in his lab at Leeds, took photographs of the B-form of DNA that were very similar to the famous one Franklin made two years later; however, his tendency to interpret the whole situation, including the pictures, under the perspective of physics rather than biology might have been the cause of his failure (Hall 2011).

At the beginning of the nineteen fifties the King's College lab purchased a highresolution Philips camera, closing an epoch of using conventional photographic cameras. Thanks to this microcamera Franklin was able to improve the resolution and sharpness of pictures. For producing X-rays she started using tubes designed by Ehrenberg and W. Spear which generated very narrow beams, ideal for the study of their dispersion in crystals (Maddox 2003: 130). At this 
time three main fronts were opened in the study of DNA structure - Pauling at Caltech, in California; Wilkins, Franklin and Gosling among others at King's College of London; and at Cambridge, with Watson and Crick at the forefront. While Pauling favored stereochemical tools above all in his research, Franklin was very concentrated on her photographic patterns, not daring to announce a whole model until she had sufficient experimental data from her photos, especially of the A-form with which she was very involved at that time, or from the measurements obtained from electronic density maps. Her view that the phosphates were placed on the outside, being responsible for the hydration of the fibers, was a successful advance on her part. In February 1952, contradicting Watson's testimony (Watson 1986: 122, Olby 1974b: 350), she considered the possibility that a double helix structure was a necessary prerequisite for explaining the constancy of bases as observed by Chargaff years before. She even affirmed that the interchange of bases was responsible for DNA idiosyncrasy. Watson and Crick on the contrary worked under the conviction that the structure must be helical but, as the former recognized, based on premises not supported by empirical data and mainly sustained by Astury's photographic patterns from 1947. For this reason they visited Wilkins, who recommended they take a look at Rosalind's photographs and reports. Ignoring his advice, they hastily submitted a report to the King College's team. The surrounding climate of competition and rivalry for success drove them to failure. As soon as Franklin saw the wrong model, she did not hesitate in recommending more crystallographic data in order to establish more solid models.

The accuracy that Franklin obtained with her pictures helped her demonstrate at the end of that year that DNA has in fact a double structure: a crystalline form named A, and a paracrystalline one, called $\mathrm{B}$. The B-form becomes visible when the humidity conditions of the sample changes. This discovery clarified doubts that had accumulated since Astbury's time, 
doubts which were due to the lack of sharpness of the photographs as a result of the long exposure needed to capture this double structure (Maddox 2003: 153). But chance came once again to help scientific advance. On a certain occasion, the fiber accidentally fell off of the sample carrier which prevented its change from one form to the other. This incidental act resulted in one of the best pictures ever made of B-form DNA, known by Franklin as Photo 51. This photo clearly evidenced a helix structure of the fiber but Franklin, according to Watson's commentaries (Watson 1986: 140), refused to see or was unable to detect it. She defended an approach that models should be built once the structure was consistently determined as a result of experimental data, especially from the spots revealed by photographic plates (Maddox 2003: 161). The influence of Bernal on this assumption was more than evident. While Pauling made use of a deductive approach on his work, starting from a chemical theoretical corpus to determine the structures, and from there to look for the confirmation supported by the crystallographic data, Bernal and Franklin worked in an inverse manner- faithful to the inductive method, they started from the observed data in the pictures 'without introducing assumptions in the form of hypothetical structures' (Olby 1974b: 374). Her profound attachment to this kind of conviction impeded her in a certain way from seeing beyond the photographs or electronic density maps and taking the risk of hypothesizing about the empirical data. This radical but commendable and cautious attitude played against the imagination and risk adopted by Watson and Crick at the time they dared to announce the DNA double helix structure and the mechanism of base replication, worthy of the Nobel Prize. The words of Crick regarding the direction taken by Franklin and the King's College team towards DNA give us a good perspective of the situation. 
In short, both the groups at King's College had obtained a fairly general idea of the structure but they had done no proper model building. Mainly because of this they had missed the pairing of the bases and they had completely overlooked the significance of Chargaff's rule (Crick 1974: 766).

In January, 1953, Pauling published his own version, defending a triple-helix structure with the phosphates placed in the center (Pauling and Corey 1953). As mentioned before, the impatience of this brilliant scientist so close to a discovery that everyone knew was coming, or his excessive confidence in the predictive power of his models, might have been good reasons for his failure. The significant role played by the photographs in this vital discovery was recognized by him years later.

I cannot say what would have happened if I had made the other assumption, that of a double helix, on November 26, or if I had succeeded in getting access to the diffraction photographs of DNA that had been made by Wilkins (Pauling 1974).

He knew Wilkins had excellent photographs taken by Franklin, but they were not available for him on time. For the formulation of his triple-helix he only had his own pictures to go on and the testimony of Corey, his collaborator, who went to King's College to take a look at those of Franklin. At the same time, Franklin was close to discovering the correct structure, working hard in applying Patterson functions to the photographic patterns. Her doubts about a double helix structure was probably due to her excessive interest in the A-form. Coincidently, Wilkins showed her pictures and results to Watson without her consent, all the material 'I could remember and scribble down from Rosie', in Wilkins own words (Olby 1974b: 396). At the end of January, 1953, Wilkins showed the Photo 51 with B-form DNA to Watson. 'The instant I saw the picture my mouth fell open and my pulse began to race' (Watson 1986: 167) 
Watson took notes of all he could remember about the photographic pattern on a newspaper, deducing at that moment that the structure should be double. That was in concordance with his earlier conviction that 'biological objects come in pairs' (Olby 1974b: 398). Two more details which Franklin did not notice until then helped the two Nobel winners dare to present a new image of DNA - the monoclinic and anti-parallel character of the fiber - the two strands of the helix run in opposite directions in consonance with bases pairs. The stereochemistry procedure and the construction of a model of a winding staircase of rods and wires helped them visualize one of the best kept secrets of nature - the continuity of life (Watson and Crick 1953).

The commentaries which testify to the importance of Franklin's diffraction patterns in this discovery are numerous - among others, the Nobel laureates themselves (Watson and Crick 1953), historians such as Olby (1974b) and Maddox (2003), Pauling (1974), or Klug (1968). To what extent an image printed in black and white was the starting point for the conquering of that knowledge, either through the abstract shaped patterns, or through the models built out of the measurements of angles and distances between spots, is an epistemological issue of great interest for the philosophy, the science and the philosophy of photography. The relationship established between the technological image, simulation and the knowledge of the chemical constraints is a constant in the development of modern science.

\section{Beyond Photography}

Even though X-ray diffraction photography can reach resolving powers of a few angströms, allowing visibility close to the atomic scale, to fully understand molecules structures it is necessary to build models which go beyond these limits. The difficulties of registering information about the phases of the waves scattered by the atomic structure of crystals has forced 
scientists to take an alternative route to overcome this limitation. It should be noted that the spectrums registered by the photographic plates provide information about three basic characteristics of the waves: amplitude, wavelength and direction. In this process the wave phase is not contemplated - 'the amount by which each wave is out of step with its neighbours' (Kendrew 1958). This information is necessary for determining crystal structure but is lost in measurement. Thus, crystallographers have been forced to build models of the crystal structure according to the data provided by pictures in order to make visible the unknown phases. The impossibility of bringing to focus the X-rays in the focal plane of an image requires that the determination of phases has to be done with help of mathematic tools, basically Patterson Functions and Fourier series.

The expression of the electron density in a crystal as a Fourier series is the mathematical equivalent of the process of image formation by light waves in an optical instrument (Hanson et.al. 1951).

Franklin herself made profuse use of Patterson functions from exhaustive measurements of densities, distances and directions of the spots appearing in the photographic plates, and linking these results with the atomic numbers involved. This procedure permitted her to display contour maps to overcome the problem of phase representation. This type of representation illustrates the electronic density of the crystal, showing the heavier atoms as prominent peaks and facilitating a 3-D vision of the structures. At the beginning of the fifties, when Franklin was carrying out her most decisive work on DNA, these operations were made with the help of calculators, quadrants and slide-rules - hard and cumbersome work (Chadarevian 2001). As matter of fact, according to Raymond Gosling, Franklin's assistant, the great difficulty for scientists was to 'think' in three dimensions. On occasions he went to buy big navel oranges 
which helped to simulate the spatial relations of multiple curves shown in the Patterson maps (Maddox 2003). Soon crystallographers developed different procedures and techniques to facilitate this kind of operation. The Lipson Diffractometer was very common. This basically consisted of the projection of trial structures represented by holes punched in an opaque mask, thus allowing a Fourier transformation of this mask to be obtained optically (Hooper et. al. 1955). However, the arrival of computers marked the initiation of a new epoch in these kinds of operations, sometimes associated with a new kind of image formation apart from gelatine silver prints - the electronic image. It is noteworthy in this context the work of Ray Pepinsky who developed an analog computer specially designed to calculate Patterson functions of crystallographic data and provided a cathode ray tube for the visualization of the results (Chadarevian 2002). Another technique oriented toward solving the problem of phase formation was to incorporate heavy atoms in the fibers. This method was implemented by Max Perutz in 1953 with the name of 'isomorphic replacement'. It determined the 3-D structure of molecules by comparing X-rays photographic patterns with and without the presence of these types of atoms. Atoms of gold or mercury were usually used because of their capacity to slightly change the spots in the photographs (Kendrew 1958). This method was crucial in the determination of the structure of hemoglobin and myoglobin by M. Perutz et. al. (1960) and J. C. Kendrew et. al. (1960) respectively, demonstrating that 3-D visions of molecular structures was an unavoidable step for advancing this area. It is necessary to insist that in the decade of the fifties, when the first outstanding advances in molecular biology were taking place, the technique of using models and the construction of 3-D objects out of photographic patterns as a direct way to observe fiber and crystal structures - above all proteins - was very complex. Among other reasons this was due to the extreme richness of detail the photographs showed in terms of intensities and positions of the 
diffracted rays. At the beginning structures were resolved by trial and error and the models were provisional until confirmed afterwards by new patterns.

In the early days of crystal analysis, the structures were solved by a process of trial and error. If we postulate an arrangement of the atoms in the crystal, it is always possible to calculate how this arrangement would scatter the X-rays and to compare these calculations with what is actually observed. If the structure has been guessed correctly, the intensities of the diffracted spots can be explained (Bragg 1954: 55).

Consequently, in order to get a clear result in 3-D, it was necessary to compare diffraction patterns of several crystals, each of them provided with heavy atoms placed in different positions. Afterwards it was necessary to compute the phases of each reflection and analyze further reflections to increase the resolving power. The first all-purpose-digital computers used in this type of calculations were the Edsac, Mark 1 and 2, Swac, or Deuce. These computers facilitated making the calculations needed to determine the phases of hundreds of reflections and the elaboration of electron density maps. The results were also visualized as plots of serial sections piled up like the serial sections of organs used by anatomists (Kendrew 1958).

\section{Discussion}

Optical instruments and image acquisition/reproduction devices such as silver halide photography as a substantial part of X-ray diffraction spectrography, made possible the observation of new physical phenomena. In the study of DNA structure, photographs made by Rosalind Franklin and many other scientists were determinant for understanding its double helix form and the replication system of the bases in the molecule. The limitations of X-ray photography for representing the wave phases necessary for inferring its structure obligated scientists to use mathematic tools such as Fourier series and Patterson functions in order to 
adequately represent this kind of phenomena. Beyond the 2-D and 3-D types of images and models, we have also seen that the production and interpretation of the images required a background of previous discoveries and understanding of biochemical and molecular biology.

We may profitably view scientific activity as a process of a building up of constraints on inquiry, reducing the degrees of freedom on our activity until a coming together of a number of aspects of a situation results in insight or understanding. Kenneth Schaffner discusses this issue in our example as one of 'controlled speculation' (Schaffner 1974). Science involves various kinds of activities that may be considered as the building of constraints - some of them social, some technical, and some theoretical with the use of logic, models, and mathematics. At the center of all this activity however is the process of creating a concrete record which serves as a focus for the activities. Regardless of how far we go in theoretical speculation, or with physical, mathematical and computer modeling, it is the concrete record to which we must constantly return, which must be accounted for. Our forays into the theoretical must always be grounded in observables - whether it be readings on a meter, the clicks of a Geiger counter, or the dots formed on a silver halide plate. In this case, as in many, theory often advanced ahead of the ability to produce an adequate record, but the models gave us guidance as to how go to about creating an image. Likewise, once a more adequate image was achieved the adequacy of the models was reconsidered, and this in turn led us back to the image to redefine the significance of the dots. In this manner science involves a movement back and forth between abstractions and the concrete.

The production of a stable, interpretable photograph was therefore the central controlling feature of this story of scientific discovery. But no description of this process will easily allow us to view the photograph as an 'objective' picture of an independent object. Instead we are led to 
consider the photograph as the product of activities of selection and choice guided by considerations generated through a long process of development and refinement of techniques. Once we have a record in the form of an image we already have first order 'data'. Data is here taken to be the output of a set of operations which transforms processes into a stable, concrete visual document which can then be further worked upon and manipulated. The various physical models and mathematical tools cannot replace the photograph. They act as a guide for exploring the photograph and this in turn gives rise to accounts of a phenomenon which guide us in looking for certain patterns and a modification of our technique to obtain new inferred qualities. Observation, looked at from this angle, is a form of 'active observation,' both in the sense that the image has to be created to meet certain criteria as well as requiring interpretation about what is 'seen'.

Photo 51 is therefore a record of a process in two senses - of the diffraction of a particular range of electromagnetic radiation by the molecules of DNA, as well as a record of the process of inquiry. It is a picture that results from the manner in which we interact with our material using a variety of instrumentalities. Being in part a record of the process of inquiry, interpreting the image requires an accompanying description of operations of production and their consequences. It says something to someone who knows about the operations that produced it. In this case the interaction of the object with the instruments used in its detection must be taken into account. Our story of 'discovery' emphasizes that in science it is not enough to see, but understanding the seen (Wilkins 2003: 141).

The foregoing account of the development of X-ray photography therefore encourages us to view scientific discovery as a process of working with instrumentalities and materials which eventuates in bringing to a close a problematic situation, terminating a line of inquiry and then 
instituting others. The moment of inference, that which pulls all the preceding work together, appears in our descriptive account but our analysis, if it is to be objective, must focus on the conditions which make that final moment possible. The moment of discovery then becomes something less than a mysterious moment of insight or genius. It is a moment when closure is achieved, when various aspects of a situation are brought together in such a way that a felt coherence is the result, and new avenues of exploration are opened. A description of 'discovery' notes the event as a pause and subsequent change in direction in the process of inquiry (Dewey 1988).

Our reason for venturing into this description of science, the status of the photograph and the historical account of its development is to counteract the tendency to minimize the importance of the photograph and its production in the process of discovery. In modern accounts of major scientific discoveries, particularly this one, the role of the empirical component of inquiry recedes into the background and is not given the attention the above considerations suggest it deserves. Instead, we focus on the moment when the significant inference is made. We suggest there are two important reasons for this selective attention, one having to do with the characteristics of inquiry within science itself, and the other having to do with the social context in which scientific activity goes on.

A discovery in science is never an end in itself, but may be seen as a temporary consolidation, a pause which introduces a re-organization of inquiry. In other words, what was once taken as problematic, the structure of DNA and its relation to the photo we obtain, comes to be settled and therefore assumed. Where initially there is active discussion of the process of making the image and its interpretation, once the issue becomes settled the photo and its subject become decontextualized and objectified and the work of producing the image fades into the 
background. It comes to have a different status for scientists-we can now assume the interpretation of the image, of what is seen, and focus on the implications for further research. This is a historical issue and reflects the progressive, inherent character of science. However if we are concerned with an analysis of the process of discovery, we cannot let slide from view the work that went into producing the image. Once we do this, we begin to demystify the process of discovery. We can no longer attribute discovery to an isolated moment, to be explained by psychological faculties such as 'insight' or 'genius'.

The other factor to which we would like to point concerns the social context in which this particular discovery was made, a context which focuses on and rewards the big discovery. We have a need or desire to locate discovery in a particular time and place and associate it with particular individuals who demonstrate insight or genius. As a result, we both mystify the process of discovery as well as ignore the work that was necessary to arrive at that 'magic' moment.

Much scientific and social attention was directed at the impending discovery of the structure of DNA. Chargaff discusses the 'publicity carnival that ensued upon the unveiling of the DNA model' and notes that this advertising was probably unique in the history of science (Chargaff 1974). In his discussion of the changes in scientific practice that have occurred since that discovery, he also notes the increasing expense of doing scientific research, the interests of investors in achieving profitable pre-determined outcomes, the increase in sheer number of people involved in mechanized research, and an overall decline in an interest in the actual, artistic process of discovery. Correspondingly, more publicity is invested in trying to understand the 'gurus' of scientific research as well as the miraculous promise of findings from very preliminary investigations. Histories of science are written which are devoid of all context about 
the actual doing of experimental work, encouraging the idea that scientists are magicians of imagination or genius. The result is the inattention to the actual process of discovery, in this case the production of a photograph of the helical structure of the DNA molecule.

Part of the reason why we ignore the empirical basis for the discovery, the doing of the photography, as well as being able to give a good account of doing science is that we haven't attended enough to the actual day-to-day process of what doing science involves. What we see today is that the accounts we are giving of this activity are so filtered, censored and highly patterned according to particular interests that we lose any possibility of seeing what the work was like.

When we take the process of arriving seriously, then we have to ask 'where was the discovery?' 'Who should receive credit?' In principle the 'discovery' could have been made by Franklin, with her patient and necessary work in producing images, or in Pauling's modeling which had already been successful for him in discovering the structure of hemoglobin. In this case however it was Watson and Crick who made the inference that was to bring together both the photo and theory. We have already seen that Pauling bemoaned his lack of access to the Franklin's images, which would have given him crucial information for his model-building. Similarly though, as Wilkins remembers: Our [his and Franklin's] main mistake was to pay too much attention to experimental evidence' (Wilkins 2003) but no less important is the dependency of all parties involved on the use of cameras and photographs to assure the validation of their assumptions. 


\section{ENDNOTES}

1 - Consejo Superior de Investigaciones Científicas. (National Scientific Research Center in Spain). 


\section{REFERENCES}

Abir- Am, P. G. (1997), 'De la colaboración multidisciplinar a la objetividad transnacional:

El espacio internacional, constitutivo de la biología molecular, 1930- 1970’, Arbor, 156:614, pp. $111-150$.

Astbury, W. T., Bell, F. O. (1938), 'X-ray Study of Thymonucleic Acid', Nature 141, 23

April, pp. 747 - 748.

Bacon, Francis (1991), Novum Organum, México: Porrúa.

Bragg, William (1933), 'Crystals of the Living Body', Nature 131, 1 - 8 July, pp. 11 - 13.

Bragg, Lawrence (1954), 'X-ray Studies of Biological Molecules', Nature 174, 10 July, pp. $55-59$.

Chadarevian, S. (2002), Designs for Life, Cambridge: Cambridge University Press.

Crick, Francis (1974), 'The double helix: a personal view', Nature 248, 26 April, pp. 766 769.

Darlington, C. D. (1955), 'The Chromosome as a Physico- Chemical Entity’, Nature 176. 17 December, pp. 1139 - 1144.

Galison, Peter (1997), 'Image and Logic. A Material Culture of Microphysics', Chicago: The University of Chicago Press.

Hall, K. (2011), 'William Astbury and the biological significance of nucleic acids, 1938 1951', Studies in History and Philosophy of Biological and Biomedical Sciences, 42, pp. 119 - 128.

Hanson, A. W., Taylor, C. A., Lipson, H. (1951), 'Fourier Synthesis by Optical Interference', Nature 168, 28 July, pp. 160 - 161. 
Hooper, C. W., Seeds, W. E., Stokes, A. R. (1955), 'Photographic Preparation of Masks of Large Molecules for the Lipson Diffractometer', Nature 175, 16 April, pp. 679 - 681.

Kendrew, J. C. (1958), 'Architecture of a Protein Molecule', Nature 182, 20 September, pp. $764-767$.

Kendrew, J.C., Dickerson, R.E., Strandberg, B.E., Hart, R.G., Davies, D. R., Phillips, D.C., Shore, V.C. (1960), 'Structure of myoglobin. A three-dimensional fourier synthesis at 2 Á. resolution', Nature 185, 13 February, pp. 422 - 426.

Klug, A. (1968), 'Rosalind Franklin and the Discovery of the Structure of DNA', Nature 219, 24 August, pp. $808-810$.

Maddox, B. (2003), Rosalind Franklin. The Dark Lady of DNA, London; Harper Collins Pub. Meinel, C. (2004), 'Molecules and Croquet Ball', in S. Chadarevian and N. Hopwood (eds.) Models: The Third Dimension of Science', Stanford: Stanford University Press, pp. 242 275.

Olby, R. (1974a), 'DNA before Watson-Crick', Nature 248, 26 April, pp. 782 - 785.

Olby, R. (1974b), The Path to the Double Helix, London: MacMillan Press.

Pauling, Linus, Corey, R. B. (1953), 'Compound Helical Configurations of Polypeptide

Chains: Structure of Proteins of the $\alpha$ - Keratin Type', Nature 171, 10 January, pp. 59 - 61.

Pauling, L. (1974), 'Molecular basis of biological specifity', Nature 248. 26 April, pp. 769 771.

Perutz, M.F., Rossmann, M.G., Cullis, A.F., Muirhead, H., Will, G., North, A. C. T. (1960), 'Structure of haemoglobin. A three-dimensional fourier synthesis at 5.5-Á resolution, obtained by X-ray analysis', Nature 185, 13 February, pp. 416 - 422. 
Schödinger, Erwin (1933), 'The fundamental idea of wave mechanics', Nobel Lecture, December 12th, 1933.

http://www.nobelprize.org/nobel_prizes/physics/laureates/1933/schrodinger-lecture.html. Accessed 20 July, 2013.

Schrödinger, Erwin (1967), What is Life?, Cambridge: Cambridge University Press.

Tutton, A. E. H. (1913), 'Great advance in Crystallography', Nature 91, 17 July, pp. 518 522.

Waddington, C. H. (1969), 'Some European Contributions to the Prehistory of Molecular Biology', Nature 221, 25 January, pp. 318 - 321.

Watson, John D., Crick, Francis H. C. (1953), 'Molecular Structure of Nucleic Acid', Nature 171, 25 April, pp. 737 - 738.

Watson, John (1986), The double Helix, New York: Atheneum.

Wilkins, M.H.F. (2003), The Third Man of the Double Helix, Oxford U.S.A.: Oxford University Press. 